\title{
Augmented Reality Sign Language Teaching Model for Deaf Children
}

\author{
Jorge Jonathan Cadeñanes Garnica and María Angélica González Arrieta \\ Department of Computer Science and Automation, Faculty of Science, \\ University of Salamanca, Spain \\ \{cadenanes, angelica\}@usal.es
}

\begin{abstract}
This article describes a Sign Language Teaching Model (SLTM) designed to develop on deaf children different Communication Skills (CS) within a Collaborative Learning Environment with MixedReality (CLEMR). A pilot lesson with the Fingerspelling Alphabet was conducted at the Association of Parents of Deaf Children of Salamanca to determine the Percentage of Development of the Sign Language Communication Skill (SLCS) and others by using a kit of Pedagogical Materials as complementary teaching resources.
\end{abstract}

Keywords: Augmented Reality, Sign Language Communication Skill, Mixed-Reality Learning Environment, Pedagogical Materials.

\section{Introduction}

The use of Information and Communication Technologies (ICT) such as the Augmented Reality (AR) has proved to be a successful educational resource for teaching SL topics at primary education $[1,17]$. In a Teaching/Learning Process it promotes the collaboration between students and teachers to the construction of knowledge within a Collaborative Learning Environment with Mixed-Reality (CLEMR) [14]. To teach SL (in preschool and primary education) it is essential to identify the diverse learning needs of deaf children in order to improve their school achievement and social integration [20]. To do this, we propose a Sign Language Teaching Model (SLTM) and a kit of Sign Language Pedagogical Materials (SLPMs) as complementary teaching resources.

The article is presented as follows: In Section 2, we mention the projects we considered are examples of how AR technology is adapted to educational purposes. In Section 3, we describe the SLTM and SLPMs we are proposing to develop SLCS and other Communication Skills (CS) on deaf children. We also present the instrument used to validate them. In Section 4, we describe the process of a pilot lesson with the Fingerspelling Alphabet at the Association of Parents of Deaf Children of Salamanca (ASPAS) [2]. On section 5, we draw some conclusions and on Section 6 we mention the future research. 


\section{Related Works}

An AR educational project proposed by Billinghurst et al. [4,5,6,7] called MagicBook covers a CLEMR in a multi-level learning experience. These three levels of collaboration are the Reality, AR and Virtual Reality (VR). On the first level, users can learn with the MagicBook as a physical object that exists in the real world with learners. They can gather around the book and interact together as peers. Also, the readers can explore the book whilst they are sharing their learning experiences in order to comprehend better the topics presented.

On the second level, a desktop application installed on networked PCs allows the visualization of animated avatars and digital environments projected on the PCs screens or AR displays. This level of collaboration allows smooth transitions from Reality to AR or vice versa. The users maintain contact with both realities while they interact with digital objects. On the last level, the users' interactions are no longer in the real world. Everything happens within computer-generated environments. Multiple users wearing AR devices can see each other as avatars. Therefore, their interactions are produced by sharing only digital information while completely immersed within a virtual environment.

With the MagicBook it is possible to learn different topics (previously established by the teachers) by moving between realities. With this technology the students can choose a learning experience from Reality to VR, depending on the skills or information (knowledge) they want to learn or experience.

The interactive desktop tool Realitat3 [17] improves learning and teaching processes by customizing several teaching subjects accordingly with thematic units for primary education. This AR program facilitates the teachers' explanation in classrooms as the same time it promotes the students' interest in learning something new through technology. The interface can be updated with new themes when needed. Their developed AR system provides a basic functionality with menus that allows the tracking of AR markers. Therefore, users can learn by exploring the 3D objects or by playing animations.

\section{Sign Language Teaching Model and the Kit of Pedagogical Materials}

The SLTM we are proposing is called: Multi-language Cycle for Sign Language Understanding (MuCy) (Fig.1). To design it we are founded on a theoretical background which encompasses the Zone of Proximal Development (ZPD) of Lev's Semionovich Vigotsky [9,12]; the Principles of Social Education for deaf and dumb children [20] and the Reality-Virtuality Continuum proposed by Paul Milgram [15]. The model is also supported by research in neuropsychology which has shown that deaf children could develop good reading and speaking skills by learning them at an early age [13].

The SLTM MuCy is cyclical to the extent that skills gained from knowledge are implemented to communicate with others in different communication systems 
such as making signs, reading, writing or speaking. Since deaf people develop different levels of Communication Skills they need an outline that helps them to develop a SLCS and other CS mentioned before through interaction with people, technology and information. That is possible when school teachers promote the CLEMR.

We present two psychomotor SL educational levels (Fig.1). The first teaches the proper use of signs with respect to their visual references (words or phrases) and their written words (the action to write down on paper the meaning of those words). The second level enables the development of speech. Hence deaf children can acquire the ability to express themselves with different communication systems when the SL system is not suitable for some social situations. Finally, the concept of CLEMR refers to the use of ICT like AR into social learning interactions. In brief, the CLEMR is similar to Vigotsky's ZPD in the sense that children learn from each other. The $\mathrm{MuCy}$ model aims to be a reference point on which deaf children can learn SL in an easy way. Hence, they will be more confident by expressing their ideas socially.

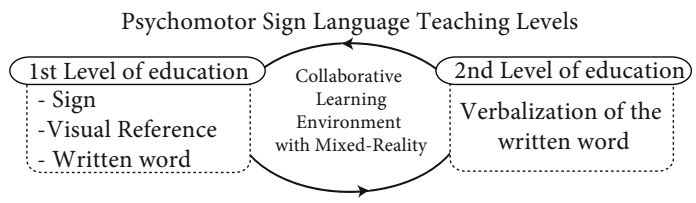

Fig. 1. Multi-language Cycle for Sign Language Understanding (MuCy model)

We are presenting a kit of SLPMs and a desktop AR application created with the Cross-platform Unity3D [18]. These educational materials (Fig.2) were designed in order to offer different SL topics for deaf and non-deaf students. Its design allows deaf students to learn in a logical and sequential way to make signs, read, write and speak.
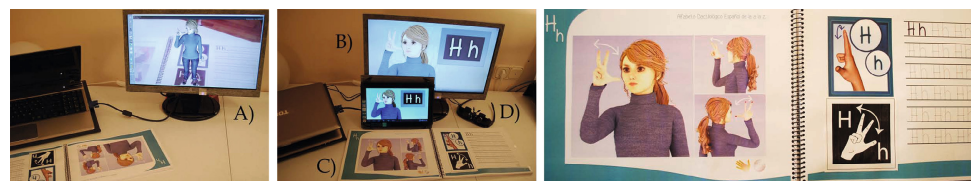

Fig. 2. Pedagogical materials as learning interfaces based on the VR-Continuum. A) An AR avatar making signs in Unity3D, B) Animations displayed on PC screen and Tablet, C) SL Book with sections for reading and writing exercises, D) Vuzix AR eyewear display.

The first SLPM is a SL Fingerspelling Alphabet book. It serves as a tangible interface that allows the use of the Vuforia marker-based tracking system for Unity3D [19]. This SL book facilitates the understanding of performing signs as 
well as the development of reading and writing skills. Words from A to Z are shown in signs printed on the SL book, as well as images of avatars performing signs with their corresponding words. The use of text to teach meanings makes possible to practice reading and writing skills as well.

For the Fingerspelling Alphabet pilot lesson we had created a set of 30 videos that can be watched on either PC screens, Tablets or AR displays. All these, are the intermediate interfaces between Reality and digital contents. With these videos as the second SLPMs children can learn to make signs by imitation. The learning experience can also be shared with other students around the screens in a CLEMR [16]. The last SLPM is the Unity3D AR application. We used Blender 2.69 [3] to model and animate the avatars. The Cross-platform game engine Unity3D facilitated us the creation of the virtual scenes on which these avatars are displayed. The file format used was the FBX that allows to display 3D objects with high definition. The Unity3D application can be adapted to be used in two modalities: With PC screens or with Head Mounted Displays (HMD) such as Vuzix [21].

To evaluate the SLTM MuCy and the SLPMs we used a Likert's scale survey of five points to measure usability, satisfaction and learning achievement. Two teachers from ASPAS and two parents of the children how participated in this Fingespelling Alphabet pilot lesson answered the survey. To design the questions (Table 1) in accordance with our teaching approach, we took into account the most relevant elements of the Principles of Learning and Teaching P-12 [11] and the Danielson's Group Framework for Teaching [10].

Table 1. Likert's scale survey to validate the MuCy model and the SLPMs

\begin{tabular}{|c|l|c|c|c|}
\hline $\mathbf{i}$ & Question & Mean & Std.Dev. & $\%$ \\
\hline Q1 & $\begin{array}{l}\text { The SLPMs help deaf children to remember information through mem- } \\
\text { orization. }\end{array}$ & 4.50 & .707 & $90 \%$ \\
\hline Q2 & $\begin{array}{l}\text { The two educational levels of the MuCy model help deaf students to } \\
\text { cognitively understand relevant information from the SL. }\end{array}$ & 5.00 & .000 & $100 \%$ \\
\hline Q3 & $\begin{array}{l}\text { Teaching Communication Skills such as reading, writing and speaking } \\
\text { help students to create solutions to the socio-cultural problems they } \\
\text { face. }\end{array}$ & 5.00 & .000 & $100 \%$ \\
\hline Q4 & $\begin{array}{l}\text { Learning with a CLEMR helps deaf students to understand a complex } \\
\text { situation in parts in order to create diverse learning solutions. }\end{array}$ & 4.50 & .707 & $90 \%$ \\
\hline Q5 & $\begin{array}{l}\text { Learning with interactive technology helps deaf children increase their } \\
\text { learning achievement. }\end{array}$ & 5.00 & .000 & $100 \%$ \\
\hline Q6 & $\begin{array}{l}\text { I would like to use these pedagogical materials as complementary } \\
\text { teaching resources either at home or at school. }\end{array}$ & 5.00 & .000 & $100 \%$ \\
\hline Q7 & $\begin{array}{l}\text { The MuCy model helps deaf children to organize their learning process } \\
\text { according to their educational needs. }\end{array}$ & 4.50 & .707 & $90 \%$ \\
\hline Q8 & $\begin{array}{l}\text { With these pedagogical materials it is easier to explain the SL posi- } \\
\text { tions to the children. }\end{array}$ & 4.50 & .707 & $90 \%$ \\
\hline Q9 & $\begin{array}{l}\text { Learning with AR avatars increases the interest in speech and makes } \\
\text { the children feel more confident that they will learn to speak. }\end{array}$ & 5.00 & .000 & $100 \%$ \\
\hline Q10 & $\begin{array}{l}\text { The SL book is an adequate tool for teaching the reading and writing } \\
\text { for an specific topic. }\end{array}$ & 4.50 & .707 & $90 \%$ \\
\hline Q11 & $\begin{array}{l}\text { The SLTM MuCy and the SLPMs promote collaborative learning ex- } \\
\text { periences. }\end{array}$ & 5.00 & .000 & $100 \%$ \\
\hline Q12 & The SL lessons are more useful and interesting with AR avatars. & 5.00 & .000 & $100 \%$ \\
\hline
\end{tabular}




\section{Fingerspelling Alphabet Pilot Lesson}

The Fingerspelling Alphabet lesson was conducted in order to measure the Percentage of Development of SLCS and other CS reached by two deaf children (Fig.3A). The lesson had a duration of one hour with students located in the same classroom. The two students aged six and seven attended the lesson together with the materials within a CLEMR.

For the lesson we made 30 videos of words from $\mathrm{A}$ to $\mathrm{Z}$ and the duration of each video was approximately 6 seconds. Hence, for every minute, each student watched and imitated an average of 8 to 10 SL positions. The lesson was divided into four activities, each of them corresponding to a specific SLPMs (Table 2).

Table 2. SL Repetitions, correct answers and total scores in one-hour lesson for the Fingerspelling Alphabet

\begin{tabular}{|c|c|c|c|c|c|c|c|c|c|c|}
\hline \multicolumn{11}{|c|}{ Fingerspelling Alphabet lesson } \\
\hline \multirow[t]{2}{*}{ Activity } & $\mathbf{T}$ (mins) & SL Reps. Goal & Sess & ion $S$ & SL Re & eps. & $\mathbf{X i}$ & $\mathbf{Y i}$ & Percent & Score \\
\hline & \multicolumn{10}{|c|}{ MS RD WR SP } \\
\hline 1 & 20 & 130 & 95 & 0 & 0 & 0 & 95 & 86 & $90.53 \%$ & 9.1 \\
\hline 2 & 10 & 65 & 0 & 58 & 0 & 0 & 58 & 51 & $87.93 \%$ & 8.8 \\
\hline 3 & 10 & 50 & 0 & 0 & 42 & 0 & 42 & 38 & $90.48 \%$ & 9.0 \\
\hline 4 & 20 & 110 & 0 & 0 & 0 & 95 & 95 & 89 & $93.68 \%$ & 9.4 \\
\hline Total & 60 & 355 & 95 & 58 & 42 & 95 & 290 & 264 & $91.03 \%$ & 9.1 \\
\hline Mean Value & 15 & 88.75 & 24 & 15 & 11 & 24 & 72.50 & 66 & $90.65 \%$ & 9.07 \\
\hline Std. Dev & & & & & & & & & & 0.24 \\
\hline
\end{tabular}

Activity one (Making Sings: MS) consisted of animated videos having children watch together the avatars performing signs on the PC screen, then they had to imitate the SL positions right after the avatars. For Activities two (Reading: RD) and three (Writing: WR), the children had to use the SL book to practice reading the words of the Alphabet. Next, they had to write those words down on the book, performing corresponding SL positions immediately after writing a word. At the last Activity (Speaking: SP), the children first had to use the

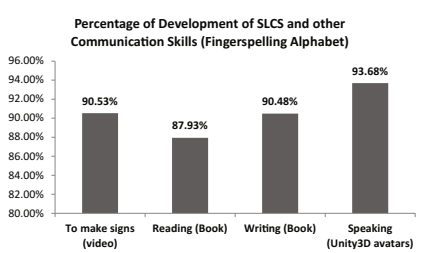

A)

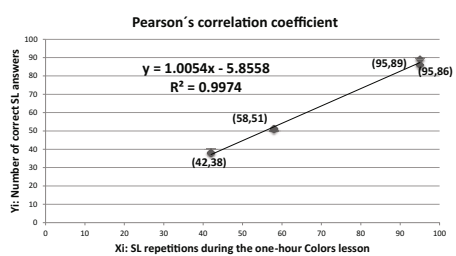

B)

Fig. 3. A) Percentage of Development of SLCS and other Communication Skills, B) Correlation analysis between the SL repetitions during the one-hour Fingerspelling Alphabet lesson and the students' correct SL answers 
markers printed on the pages to display the animated avatars on the PC screen, then teachers taught the students to move their lips and tongues to reproduce sounds and to practice speech.

\section{Conclusions}

In this paper we have presented a SLTM called Multi-language Cycle for Sign Language Understanding $(\mathrm{MuCy})$ and a Kit of Pedagogical Materials to teach SL to deaf children at ASPAS. A Fingerspelling Alphabet pilot lesson within a CLEMR was conducted in order to determine the Percentage of Development of the SLCS and other CS of two deaf children aged six and seven.

It also has been proved that by using ICT technology such as AR avatars increases child interest on speech (Table 1, Q9 and Q12). By using the $\mathrm{MuCy}$ model and the SLPMs deaf children developed the SLCS with a $90.53 \%$ improvement, for writing skills a $90.48 \%$ improvement, for reading skills a $87.93 \%$ improvement, and for speaking skills a $93.68 \%$ improvement (Fig.3A). The Total Mean Value of the two students' SL Correct Answers was $90.65 \%$ development (Table 2).

Mindful of psychomotor relationships between knowledge and communication, it is observed that there is a strong correlation coefficient of $0.99 \%$ (Fig.3B) between the SL repetitions from the one-hour Fingerspelling Alphabet lesson and the number of Correct Answers given by the children. It is established that the more they practice SL positions (reading, writing and speaking through the SLPMs) the more they learn to communicate. With cognitive relationships between knowledge and communication, deaf people are able to understand SL concepts through imitation, by watching images or by interacting with technological interfaces (either tangible or digital).

The main contributions of this SLTM are: Firstly, it promotes the development of Communication Skills such as making signs, writing, reading and speaking. Secondly, it establishes the SLPMs which can be used as complementary teachings resources. And finally, it allows deaf children to acquire knowledge within a CLEMR. SL teachers have on their hands a complementary SLTM which ensures the full understanding of concepts, meanings or ideas in accordance to their SL study programs.

\section{Future Research}

The next step to improve our proposed MuCy model is to keep testing it by conducting another SL pilot lesson with the Rainbow Colors at ASPAS and other deaf people associations and schools. With this, we will be able to make data comparisons between the Alphabet and the Colors lessons in order to have a finalized and tested SLTM and SLPMs with at least two different topics. The core idea is to gradually add more complex SL topics.

Microsoft Research China has demonstrated recognition in real time SL movements performed by a person facing the Kinect camera [8]. Therefore, we 
also plan to create one more SLPM based on Blender and OpenKinect camera for capture the motion of face, hands and body. So there will be a SL Networkedapplication that will reproduce and translate sounds, text and images remotely and in real time using Augmented Reality.

Acknowledgments. The authors would like to thank to ASPAS for all the support provided and for the opportunity to facilitate to their students the development of SLCS and other CS with a SLTM and its SLPMs.

\section{References}

1. Adamo-villani, N., Carpenter, E., Arns, L.: 3D Sign Language Mathematics in Immersive Environment. In: Proc. of ASM 2006 - 15th International Conference on Applied Simulation and Modeling, Rhodes, Greece (2006)

2. Association of Parents of Deaf Children of Salamanca, ASPAS, Spain (2014), http://www.aspas-salamanca.es/ (viewed on July 6, 2013)

3. Blender Foundation, Blender 2.69 (2014), http://www.blender.org/ (viewed on September 1, 2013)

4. Billinghurst, M., Kato, H., Poupyrev, I.: The Magic Book: A Transitional AR Interface. Computers and Graphics 25(5), 745-753 (2001)

5. Billinghurst, M., Kato, H., Poupyrev, I.: The MagicBook. Moving Seamlessly between Reality and Virtuality. Human Interface Technology Laboratory, University of Washington, Hiroshima City University and Sony Computer Science Laboratories $(2001)$

6. Billinghurst, M., Kato, H., Poupyrev, I.: MagicBook: Transitioning between Reality and Virtuality. In: Proceeding Extended Abstracts on Human Factors in Computing Systems, New York, NY, pp. 25-26 (2001)

7. Billinghurst, M., Kato, H., Poupyrev, I.: Collaboration with tangible Augmented Reality Interfaces. Human Interface Technology Laboratory, University of Washington, Hiroshima City University and Sony Computer Science Laboratories (2002)

8. Chai, X., Li, G., Lin, Y., Xu, Z., Tang, Y., Chen, X.: Sign Language Recognition and Translation with Kinect. Key Lab of Intelligent Information Processing of Chinese Academy of Sciences (CAS). Institute of Computing Technology, Microsoft Research Asia, Beijing, China (2013)

9. Chaiklin, S.: Vygotsky's educational theory and practice in cultural context. The zone of proximal development in Vygotsky's analysis of learning and instruction. Cambridge University Press (2003)

10. Danielson, C.: The framework for teaching. Evaluation instrument. The Danielson Group (2013), http://www.danielsongroup.org (Viewed on December 1, 2013)

11. Department of Education and Early Childhood Development. The Principles of Learning and Teaching P-12 Unpacked (2014), http://www.education.vic.gov.au (Viewed on January 10, 2014)

12. Ivic, I.: Lev Semionovich Vygotsky. UNESCO 24(3-4), 773-799 (1994)

13. Mayberry, R.I.: Cognitive development in deaf children: the interface of language and perception in neuropsychology. In: Segalowitz, S.J., Rapin, I. (eds.) Handbook of Neuropsychology, Part. II, 2nd edn., vol. 8 (2002) 
14. Mertzani, M.: Considering Sign Language and Deaf Culture in Computer Mediated Communication Environments: Initial Explorations and Concerns. In: 9th Theoretical Issues in Sign Language Research Conference, Florianopolis, Brazil (2008)

15. Milgram, P., Takemura, H., Utsumi, A., Kishino, F.: Augmented Reality: A class of displays on the reality-virtuality continuum. In: SPIE, vol. 2351. ATR Communication Systems Research Laboratories, Kyoto (1994)

16. Pemberton, L., Winter, M.: Collaborative Augmented Reality in Schools. In: Proc. CSCL 2009, vol. 2, pp. 109-111 (2009)

17. Salvador-Herranz, G., Pérez-López, D., Ortega, M., Soto, E., Alcañiz, M., Contero, M.: Manipulating Virtual Objects with your hands: A case study on applying Desktop Augmented Reality at the Primary School. In: 46th Hawaii International Conference on System Sciences (2013)

18. Unity Technologies, Unity3D V4.3 (2014), http://unity3d.com/unity (viewed on October 5, 2013)

19. Vuforia Developer, Vuforia ${ }^{\mathrm{TM}}$ SDK, Unity extension Vuforia-2.8 (2014), https://developer.vuforia.com/resources/sdk/unity (viewed on December 22, 2013)

20. Vygotsky, L.: The principles of social education of deaf and dumb children in Russia. In: Proceedings of the International Conference on the Education of the Deaf, London, pp. 227-237 (1925)

21. Vuzix Corporation (2014). Wrap 920AR and 1200DXAR Eyewear (2014), http://www.vuzix.com/ (viewed on December 22, 2013) 